\title{
Oxide Ion Conductivity in the Hexagonal Perovskite Derivative $\mathrm{Ba}_{3} \mathrm{MoNbO}_{8.5}$
}

\author{
Sacha Fop ${ }^{\dagger}$, Janet M. S. Skakle ${ }^{\dagger}$, Abbie C. Mclaughlin*†, Paul A. Connor ${ }^{\ddagger}$, John T. S. Irvine ${ }^{\ddagger}$, \\ Ronald I. Smith ${ }^{\S}$ and Eve J. Wildman ${ }^{\dagger}$ \\ ${ }^{\dagger}$ The Chemistry Department, University of Aberdeen, Meston Walk, Aberdeen, AB24 3UE, UK. \\ ‡ School of Chemistry, University of St Andrews, St Andrews, Fife KY16 9ST, UK. \\ $\S$ ISIS Facility, Rutherford Appleton Laboratory, Harwell, Didcot OXı1 oDE, UK.
}

KEYWORDS Perovskite; fuel cell, oxide ion conduction.

\begin{abstract}
Oxide ion conductors are important materials with a range of technological applications and are currently used as electrolytes for solid oxide fuel cells (SOFCs) and solid oxide electrolyser cells (SOECs). Here we report the crystal

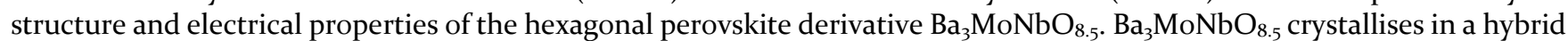
of the $9 \mathrm{R}$ hexagonal perovskite and palmierite structures. This is a new and so far unique crystal structure that contains a disordered distribution of $(\mathrm{Mo} / \mathrm{Nb}) \mathrm{O}_{6}$ octahedra and $(\mathrm{Mo} / \mathrm{Nb}) \mathrm{O}_{4}$ tetrahedra. $\mathrm{Ba}_{3} \mathrm{MoNbO}_{8.5}$ shows a wide stability range and

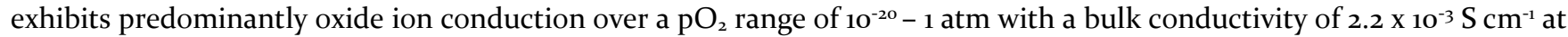
$600{ }^{\circ} \mathrm{C}$. The high level of conductivity in a new structure family suggests that further study of hexagonal perovskite derivatives containing mixed tetrahedral and octahedral geometry could open up new horizons in the design of oxygen conducting electrolytes.
\end{abstract}

\section{INTRODUCTION}

Oxide ion conductors have received much attention in recent years due to their application as electrolytes for solid oxide fuel cells (SOFCs) and solid oxide electrolyser cells (SOECs), oxygen sensors and oxygen separation membranes ${ }^{1-9}$. So far several series of fast oxide ion conductors have been reported including fluorite-like systems ${ }^{3}, 6$, silicon and germanium apatites ${ }^{10}, \mathrm{La}_{2} \mathrm{Mo}_{2} \mathrm{O}_{9}$ (LAMOX) materials ${ }^{7}, \mathrm{Bi}_{4} \mathrm{~V}_{2} \mathrm{O}_{11}$ derivatives ${ }^{11}$ and complex oxides with $\mathrm{GaO}_{4}$ tetrahedral moieties 9,12. SOFCs are highly efficient devices that convert chemical energy into electrical energy and require an electrolyte material with specific properties. A good SOFC electrolyte must exhibit negligible electron conductivity, high oxide ion transport and stability in both oxidising and reducing atmospheres as it is in contact with both the anode and cathode side of the fuel cell. For ease of manufacture and variable temperature applications it is desirable to lower the SOFCs' operating temperature to an intermediate range $\left(400-600{ }^{\circ} \mathrm{C}\right)$. The oxide ion conductivity of a material is strongly dependent on the crystal structure and hence in order to reach this objective, it is important to discover and characterise new structural families of oxide ion conducting materials.

The perovskite family appears to offer great potential for the discovery of new oxide ion conductors due to its capability of adopting numerous structural derivatives. Several perovskite materials with sizeable oxide ion conductivity have been reported including strontium and magnesiumdoped lanthanum gallates (LSGM) ${ }^{13}$ and more recently the well-known ferroelectric material $\mathrm{Na}_{0.5} \mathrm{Bi}_{0.5} \mathrm{TiO}_{3}{ }^{8}$. Hexagonal perovskites form when $\mathrm{BO}_{6}$ octahedra share faces and different stacking sequences of the cubic (corner-sharing $\mathrm{BO}_{6}$ octahedra) and hexagonal (face-sharing $\mathrm{BO}_{6}$ octahedra) $\mathrm{AO}_{3}$ layers can give rise to a variety of unique crystal structures. There have been accounts of hexagonal systems exhibiting mixed oxide ion and electronic conductivity but these materials tend to exhibit low conductivities and low transport numbers ${ }^{14-16}$.

Here we report the crystal structure and electrical properties of the hexagonal perovskite derivative $\mathrm{Ba}_{3} \mathrm{MoNbO}_{8.5}$. A bulk conductivity of $2.2 \times 10^{-3} \mathrm{~S} \mathrm{~cm}^{-1}$ is observed at $600{ }^{\circ} \mathrm{C}$ which is comparable to other prominent oxide ion conductors ${ }^{1-12}$. $\mathrm{Ba}_{3} \mathrm{MoNbO}_{8.5}$ crystallises in a hybrid of the $9 \mathrm{R}$ hexagonal and palmierite structures ${ }^{17,18}$. The crystal structure contains both $\mathrm{Mo} / \mathrm{NbO}_{6}$ octahedra and $\mathrm{Mo} / \mathrm{NbO}_{4}$ tetrahedra with intrinsic oxygen vacancies.

\section{EXPERIMENTAL}

$\mathrm{Ba}_{3} \mathrm{MoNbO}_{8.5}$ samples were prepared by solid-state reaction of stoichiometric amounts of $\mathrm{BaCO}_{3}$ (99.999\%, Aldrich), $\mathrm{MoO}_{3}$ (99.5+\%, Aldrich) and $\mathrm{Nb}_{2} \mathrm{O}_{5}$ (99.99\%, Aldrich). The starting materials were ground, pressed into a pellet and calcined in an alumina crucible at $900{ }^{\circ} \mathrm{C}$ for 10 hours. The pellet was subsequently reground, pelleted and heated at $1100{ }^{\circ} \mathrm{C}$ for 48 hours and then cooled to room 
temperature at $5{ }^{\circ} \mathrm{C} / \mathrm{min}$. The latter heating step was repeated until a phase pure product was obtained.

Room temperature X-ray powder diffraction patterns were collected on a PANalytical X'Pert Powder diffractometer equipped with a $\mathrm{Cu} \mathrm{K} \alpha$ tube. Data were recorded in the range $20^{\circ}<2 \theta<70^{\circ}$, with a step size of $0.013^{\circ}$. Time of flight (TOF) neutron powder diffraction experiments were performed on the General Material Diffractometer (GEM) at the ISIS spallation source (Rutherford Appleton Laboratory, Harwell Oxford, United Kingdom) at ambient temperature on 5 grams of $\mathrm{Ba}_{3} \mathrm{MoNbO}_{8.5}$ sealed in an $8 \mathrm{~mm}$ vanadium can. Data were acquired in the TOF range $500-$ $18000 \mu$ s using the four bank detectors with a total scan time of 2 hours.

The oxygen content of $\mathrm{Ba}_{3} \mathrm{MoNbO}_{8.5}$ was determined by thermogravimetric analysis in $\mathrm{N}_{2}$ and $\mathrm{O}_{2}$ atmospheres using a Stanton Redcroft 780 thermal analyser. $\mathrm{Ba}_{3} \mathrm{MoNbO}_{8.5}$ was heated under an oxygen flow of $50 \mathrm{~mL} / \mathrm{min}$ from room temperature to $600{ }^{\circ} \mathrm{C}$ at $5{ }^{\circ} \mathrm{C}$ per minute and then held at $600{ }^{\circ} \mathrm{C}$ for 14 hours. This was then repeated with a nitrogen flow of $50 \mathrm{~mL} / \mathrm{min}$.

For the impedance spectroscopy measurements, a pellet of $\sim 10 \mathrm{~mm}$ diameter and $\sim 1.5 \mathrm{~mm}$ thickness was prepared from a powder sample of $\mathrm{Ba}_{3} \mathrm{MoNbO}_{8.5}$ and sintered at 1100 ${ }^{\circ} \mathrm{C}$ for 48 hours (to achieve $>95 \%$ of the theoretical density). Pt electrodes were painted on both sides of the pellet using a Pt-paste (Metalor 6o82). Impedance spectra were recorded with a Solartron 1260 impedance analyser in the frequency range $0.1 \mathrm{~Hz}-1 \mathrm{MHz}$ with an applied alternating voltage of $0.1 \mathrm{~V}$. Data were recorded upon cooling from 600 ${ }^{\circ} \mathrm{C}$ to $300{ }^{\circ} \mathrm{C}$ in a sealed tube furnace under the flow of dry and moist air, measuring every $15^{\circ} \mathrm{C}$ and allowing 2 hours of equilibration at each temperature step. The obtained data were corrected by the geometrical factor of the sample and treated with the ZView software (Scribner Associates, Inc.).

Concentration cell measurements were performed on a pellet of $\mathrm{Ba}_{3} \mathrm{MoNbO}_{8.5}$ with $97 \%$ of the theoretical density. The sample was coated on both faces with Pt-paste and cemented on to the holder to assure gas tightness. Open circuit voltages were recorded on cooling from $600{ }^{\circ} \mathrm{C}$ to 450 ${ }^{\circ} \mathrm{C}$ every $50^{\circ} \mathrm{C}$, leaving enough time for the sample to reach equilibrium with the surrounding atmosphere, using a Solartron 1287 electrochemical interface. In all of the measurements one side of the pellet was exposed to a flow of dry air and the other to dry flows of oxygen or a mixture of $5 \%$ hydrogen in argon.

The conductivity dependence on the oxygen partial pressure $\left(\mathrm{pO}_{2}\right)$ of a porous pellet of $\mathrm{Ba}_{3} \mathrm{MoNbO}_{8.5}$ with $\sim 70 \%$ of the theoretical density was recorded at $600{ }^{\circ} \mathrm{C}$ over a $\mathrm{pO}_{2}$ range of $1-10^{-27} \mathrm{~atm}$ (monitored with a YSZ sensor). The $\mathrm{pO}_{2}$ range was controlled over the $1-10^{-4}$ atm range by dilution of $\mathrm{O}_{2}$ with $\mathrm{Ar}$ and for less than $10^{-20}$ atm by $5 \% \mathrm{H}_{2}$ in an argon flow. The conductivity was continuously measured using a Keithley 182 Sensitive Digital Voltmeter with a four electrode configuration.

\section{RESULTS}

\section{Sample Characterisation}

$\mathrm{Ba}_{3} \mathrm{MoNbO}_{8.5}$ has an oxygen stoichiometry between that of the $9 \mathrm{R}$ polytype ${ }^{17}$ and the palmierite structure ${ }^{18}$. An electron diffraction and high resolution electron microscopy study previously showed that the oxygen defects with respect to the ${ }_{9} \mathrm{R}$ polytype (hhc) ${ }_{3}$ leads to an ordered distribution of octahedra and tetrahedra in a 3:2 ratio in the cubic layers ${ }^{19}$. The X-ray diffraction pattern of $\mathrm{Ba}_{3} \mathrm{MoNbO}_{8.5}$ could be indexed with the space group $R \overline{3} m \mathrm{H}(a=5.921$ (1) $\AA$; $c=21.0908$ (2) $\AA$ ) in agreement with previous results ${ }^{19}$ and there was no evidence of impurities. X-ray diffraction data were also recorded after $\mathrm{Ba}_{3} \mathrm{MoNbO}_{8.5}$ was annealed at $600{ }^{\circ} \mathrm{C}$ for 24 hours in flowing $\mathrm{O}_{2}, \mathrm{~N}_{2}$ and $5 \% \mathrm{H}_{2} / \mathrm{N}_{2}$. The $\mathrm{X}$-ray diffraction data show that post annealing there is no change in crystal structure with no evidence of impurities and that $\mathrm{Ba}_{3} \mathrm{MoNbO}_{8.5}$ is stable at temperatures between 20 ${ }^{\circ} \mathrm{C}$ and $650{ }^{\circ} \mathrm{C}$ and at temperatures $>1100{ }^{\circ} \mathrm{C}$. $\mathrm{Ba}_{3} \mathrm{MoNbO}_{8.5}$ was also annealed in $5 \% \mathrm{H}_{2} / \mathrm{N}_{2}$ at a higher temperature of $1200{ }^{\circ} \mathrm{C}$ for 24 hours with no evidence of impurity phases in the X-ray diffraction pattern, indicating that $\mathrm{Ba}_{3} \mathrm{MoNbO}_{8.5}$ is surprisingly stable in $5 \% \mathrm{H}_{2} / \mathrm{N}_{2}$ (Supplementary Figure 1). The results demonstrate that the $\mathrm{Ba}_{3} \mathrm{MoNbO}_{8.5}$ phase presents wider phase stability range under reducing conditions than other leading oxide ion conductors such as LAMOX ${ }^{20}$ and the Bi and Ce oxides 5 .

\section{Conductivity of $\mathrm{Ba}_{3} \mathrm{MoNbO}_{8.5}$}

The electrical properties of a $95 \%$ dense pellet of $\mathrm{Ba}_{3} \mathrm{MoNbO}_{8.5}$ were measured by a.c. impedance spectroscopy between $300-600{ }^{\circ} \mathrm{C}$. A typical impedance spectrum of $\mathrm{Ba}_{3} \mathrm{MoNbO}_{8.5}$ recorded in dry air at $315{ }^{\circ} \mathrm{C}$ is presented in Figure 1 (a). An electrode response is observed in the low frequency region at all temperatures which is indicative of ionic conduction in a material with partially blocking electrodes ${ }^{21}$. The bulk and grain boundary responses are evidenced at higher frequencies with respective capacitance values of $C_{\mathrm{B}} \sim 6.0 \mathrm{pF} \mathrm{cm}^{-1}$ and $\mathrm{C}_{\mathrm{Gb}} \sim 0.15 \mathrm{nF} \mathrm{cm} \mathrm{cm}^{-1}$. The complex impedance plots, $\mathrm{Z}^{*}$, show that the bulk arc is visible at temperatures up to $450{ }^{\circ} \mathrm{C}$. As the temperature increases, the grain boundary arc along with a low slope electrode element indicative of Warburg type diffusion is observed. At the highest temperatures the electrode response is the main component, and turns over as might be expected for finite length Warburg diffusion (Figure 1 (b)). Such evolution is indicative of oxide ion mobility ${ }^{21}$. Furthermore the electrode response was found to become less resistive when the oxygen content of the atmosphere increased, strongly indicating oxide ion mobility. Equivalent circuit analysis was utilised to extract the individual bulk, grain boundary and electrode responses at each temperature (see Supplementary Information). 
(a)

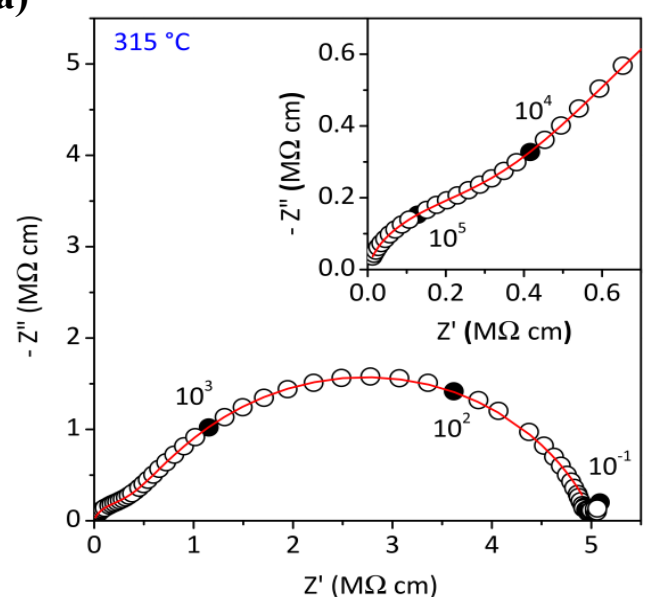

(c)

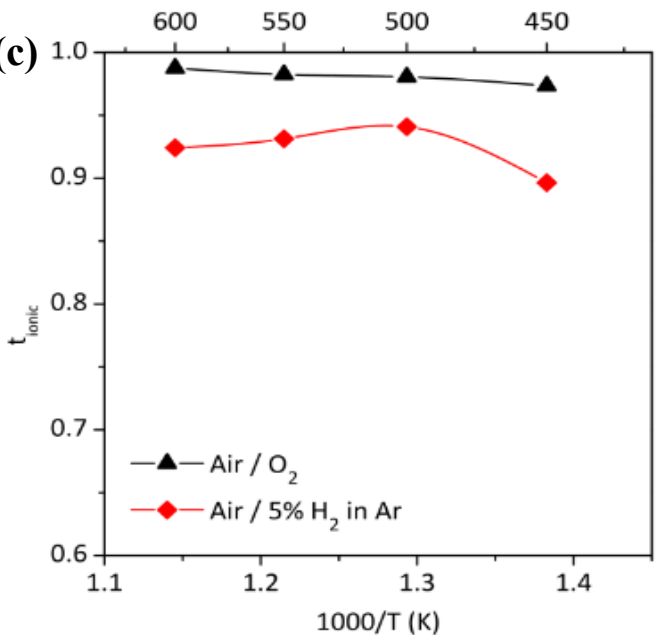

(b)

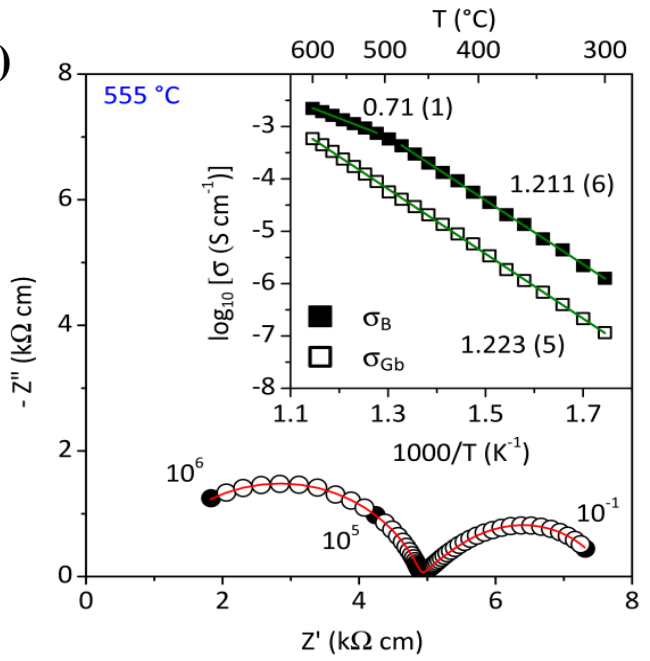

(d)

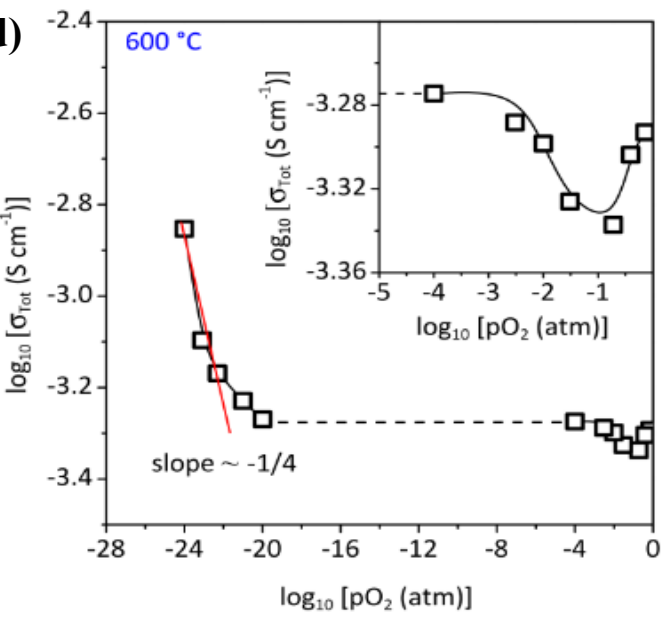

Figure 1. Ionic conductivity of $\mathrm{Ba}_{3} \mathrm{MoNbO}_{8.5}$ (a), (b) Complex impedance plots recorded in dry air at (a) $315{ }^{\circ} \mathrm{C}$, with inset showing a magnification of the high frequency data, and (b) $555^{\circ} \mathrm{C}$, with the Arrhenius plot of the bulk and grain boundary conductivity displayed in the inset. (c) Oxygen transport number over the temperature range $450-600{ }^{\circ} \mathrm{C}$ measured by the oxygen concentration cell method. (d) Dependence of the total conductivity vs $\mathrm{pO}_{2}$. The numbers and corresponding filled circles in (a) and (b) indicate selected frequencies (in $\mathrm{Hz}$ ), while the red line is the equivalent circuit fitting. In the inset to (b), the green line is the linear fit to the data and the numbers are the activation energies (in $\mathrm{eV}$ ).

The Arrhenius plot of the grain boundary and bulk conductivity of $\mathrm{Ba}_{3} \mathrm{MoNbO}_{8.5}$ is presented in Figure 1 (b). The grain boundaries constitute the most resistive part, thus dominating the total resistivity of the material. The grain boundary conductivity is $5.9 \times 10^{-4} \mathrm{~S} \mathrm{~cm}^{-1}$ at $600{ }^{\circ} \mathrm{C}$ with an activation energy of $1.223 \pm 0.015 \mathrm{eV}$. . The bulk conductivity is $2.2 \times 10^{-3} \mathrm{~S} \mathrm{~cm}^{-1}$ at $600{ }^{\circ} \mathrm{C}$ with an activation energy of $1.211 \pm 0.016 \mathrm{eV}$. A change in slope is evidenced at temperatures $>500{ }^{\circ} \mathrm{C}$, with the activation energy lowering to 0.71 $\pm 0.018 \mathrm{eV}$. At $600{ }^{\circ} \mathrm{C}$ the bulk conductivity is comparable

to other leading solid oxide electrolyte materials such as $\mathrm{Na}_{0.5} \mathrm{Bi}_{0.5} \mathrm{TiO}_{3}{ }^{8}, \quad \mathrm{Zr}_{0.92} \mathrm{Y}_{0.08} \mathrm{O}_{1.96}{ }^{22}$, LAMOX ${ }^{7}$ and $\mathrm{La}_{0.9} \mathrm{Sr}_{0.1} \mathrm{Ga}_{0.9} \mathrm{Mg}_{0.1} \mathrm{O}_{2.9}{ }^{13}$ and much greater than perovskite derivatives such as $\mathrm{Ba}_{2} \mathrm{In}_{2} \mathrm{O}_{5}{ }^{23}$ and $\mathrm{NdBaInO}_{4}{ }^{24}$. $\mathrm{NdBaInO}_{4}$ has an ionic conductivity of $\sim 1 \mathrm{x} \mathrm{10}^{-6} \mathrm{~S} \mathrm{~cm}^{-1}$ at $600{ }^{\circ} \mathrm{C}$ (Fig- ure 2) although it has recently been shown that it is possible to further enhance the ionic conductivity of $\mathrm{NdBaInO}_{4}$ by substitution of $\mathrm{Sr}^{2+}$ for $\mathrm{Nd}^{3+} ; \mathrm{Nd}_{0.9} \mathrm{Sr}_{\mathrm{o} .1} \mathrm{BaInO}_{4}$ has an ionic conductivity of $\sim 1 \times 10^{-4} \mathrm{~S} \mathrm{~cm}^{-1}$ at $600{ }^{\circ} \mathrm{C}^{25}$.

Electromotive force (EMF) measurements using an oxygen concentration cell at selected temperatures between $450{ }^{\circ} \mathrm{C}$ and $600{ }^{\circ} \mathrm{C}$ showed oxygen transport numbers of $0.97-0.99$ in air $/ \mathrm{O}_{2}$ and $0.90-0.94$ in $\operatorname{air} / 5 \% \mathrm{H}_{2}$ in $\mathrm{Ar}$, suggesting that $\mathrm{Ba}_{3} \mathrm{MoNbO}_{8.5}$ is an oxide ion conductor with negligible electrical conductivity in air $/ \mathrm{O}_{2}$ and that a small amount of electronic conduction is observed in air $/ 5 \% \mathrm{H}_{2}$ in $\mathrm{Ar}$ (Figure 1(c)). The temperature dependence of the conductivity recorded in a wet air flow resulted in a reduction in both the bulk and total conductivity compared to the same measurement in a dry air flow. This suggests that there is no proton conduction in this material 
(Figure 4 in the Supporting Information). Degradation of the electrical conductivity with time has been seen in other promising oxide ion conductors, for example in the $\mathrm{Bi}_{4} \mathrm{~V}_{2} \mathrm{O}_{11}$ derivatives ${ }^{26}$. Conductivity data versus time were recorded at $600{ }^{\circ} \mathrm{C}$ and there was no evidence of degradation of the conductivity during the 12 days that the impedance spectra were recorded. (Figure 5 in the Supporting Information).

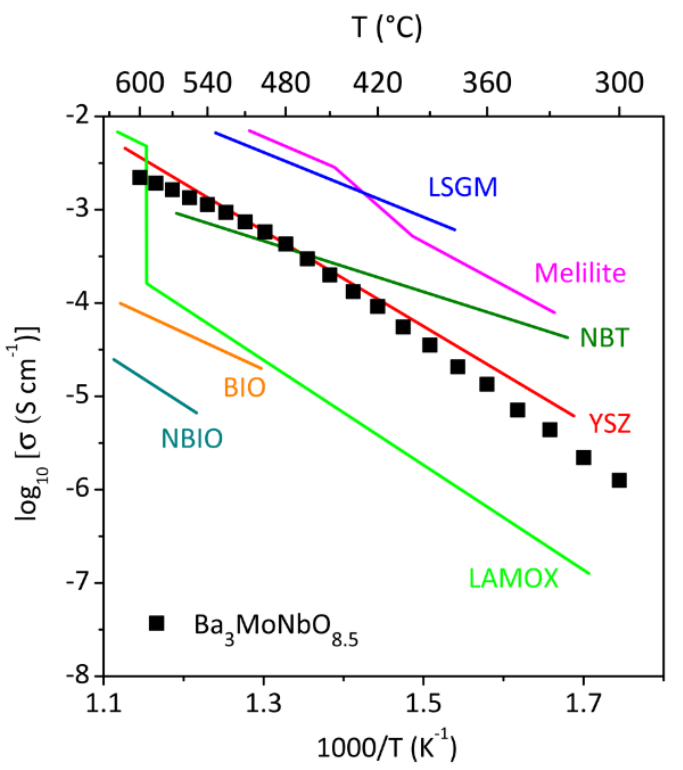

Figure 2. Comparison of bulk conductivities for $\mathrm{Ba}_{3} \mathrm{MoNbO}_{8.5}$ and other ionic conductors. Shown are $\mathrm{Zr}_{0.92} \mathrm{Y}_{0.08} \mathrm{O}_{1.96}$ (YSZ, ref. 22) , $\mathrm{La}_{0.9} \mathrm{Sr}_{0.1} \mathrm{Ga}_{0.8} \mathrm{Mg}_{0.2} \mathrm{O}_{3}$ (LSGM, ref. 13), $\mathrm{La}_{2} \mathrm{Mo}_{2} \mathrm{O}_{9}$ (LAMOX, ref. 7), $\mathrm{Na}_{0.5} \mathrm{Bi}_{0.5} \mathrm{TiO}_{3}$ (NBT, ref. 8), $\mathrm{La}_{1.54} \mathrm{Sr}_{0.46} \mathrm{Ga}_{3} \mathrm{O}_{7.27}$ (Melilite, ref. 9), $\mathrm{Ba}_{2} \mathrm{In}_{2} \mathrm{O}_{5}$ (BIO, ref. 23) and $\mathrm{NdBaInO}_{4}$ (NBIO, ref. 24).

Figure $1(\mathrm{~d})$ shows the $p \mathrm{O}_{2}$ dependence of the total conductivity of $\mathrm{Ba}_{3} \mathrm{MoNbO}_{8.5}$ at $600{ }^{\circ} \mathrm{C}$. At oxygen partial pressures $<10^{-20} \mathrm{~atm}$, an electronic n-type contribution to the total conductivity is evidenced. At oxygen partial pressures $<10^{-20} \mathrm{~atm}$, reduction of the $\mathrm{Mo}^{6+}$ and/or $\mathrm{Nb}^{5+}$ cations results in the formation of oxygen vacancies and electronic defects. The latter exhibit greater mobility than the oxygen vacancies so that the conductivity is dominated by the concentration of the electronic defects, which is proportional to $\mathrm{pO}_{2}{ }^{-1 / 4}$. The conductivity appears to be independent of oxygen partial pressure over the range $10^{-20}-10^{-4} \mathrm{~atm}$. There is evidence of a plateau between $p \mathrm{O}_{2}=10^{-20}-10^{-4} \mathrm{~atm}$, indicating oxide ionic conductivity with negligible electronic conduction over this range of $p \mathrm{O}_{2}$.

Between $p \mathrm{O}_{2}=10^{-3}-1$ atm the variation of the total conductivity with oxygen partial pressure is unusual. Upon increasing $p \mathrm{O}_{2}$ from $10^{-3}-0.21$ atm the total conductivity decreases. As $\mathrm{pO}_{2}$ increases further from $0.21-1 \mathrm{~atm}$ the total conductivity rises so that there is a minimum in $\sigma_{\text {tot }}$ at $p \mathrm{O}_{2}$ $=0.21$. The transport number recorded in air $/ \mathrm{O}_{2}$ at $600{ }^{\circ} \mathrm{C}$ is 0.99 . Thermogravimetric analysis data recorded at 600 ${ }^{\circ} \mathrm{C}$ in both flowing $\mathrm{N}_{2}$ and $\mathrm{O}_{2}$ showed no significant oxygen gain or loss, suggesting that the presence of the conductivity minimum cannot be related to any significant change of the overall phase composition. One possibility is that at $p \mathrm{O}_{2}>0.21 \mathrm{~atm}$ the increase in $\sigma_{\text {tot }}$ is a result of a structural change such as a redistribution or ordering of the oxygen vacancies. Variable temperature neutron diffraction experiments in flowing oxygen, nitrogen and air will be required to corroborate this. An alternative scenario is that these changes are related to changes in composition at the grain boundary at high temperatures and high $\mathrm{pO}_{2}$.

\section{Neutron Diffraction}

(a)

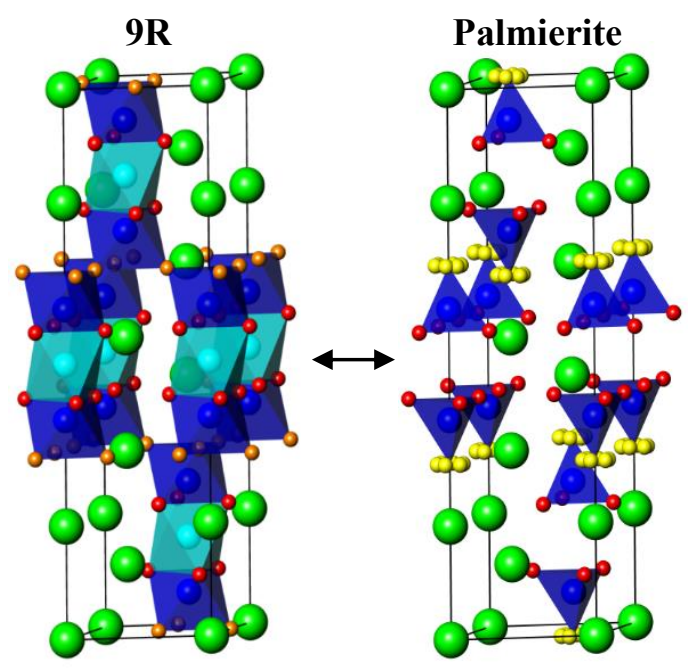

(b)
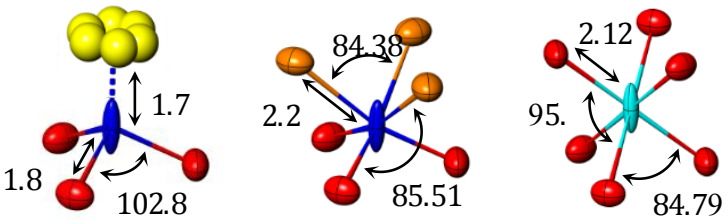

Figure 3. Crystal structure of $\mathrm{Ba}_{3} \mathrm{MoNbO}_{8.5}$ (a) The hybrid structural model formed by the superimposition of the $9 \mathrm{R}$ polytype and the palmierite sub-units representing the average structure of the system. (b) Bond lengths and angles of the $(\mathrm{Mo} / \mathrm{Nb}) \mathrm{O}_{4}$ tetrahedra and $(\mathrm{Mo} / \mathrm{Nb}) \mathrm{O}_{6}$ octahedra, with thermal ellipsoids. Colours in (a) and (b) indicate: green $\mathrm{Ba}(1) / \mathrm{Ba}(2)$, blue $\mathrm{Mo}(1) / \mathrm{Nb}(1)$, cyan $\mathrm{Mo}(2) / \mathrm{Nb}(2)$, red $\mathrm{O}(1)$, orange $\mathrm{O}(2)$ and yellow $\mathrm{O}(3)$.

In order to further investigate the crystal structure of $\mathrm{Ba}_{3} \mathrm{MoNbO}_{8.5}$, time-of-flight powder neutron diffraction data were recorded at $30{ }^{\circ} \mathrm{C}$ on the GEM diffractometer at the ISIS pulsed spallation source. Rietveld refinement ${ }^{27}$ of the crystal structure was performed using the GSAS package with the EXPGUI interface ${ }^{28,29}$. The background was fitted by the Chebyschev polynomial function and the peak shapes were modelled using a pseudo-Voigt function. $\mathrm{Ba}_{3} \mathrm{MoNbO}_{8.5}$ has previously been described to have intrinsic oxygen vacancies and intertwined regions of $\mathrm{Mo} / \mathrm{NbO}_{6}$ octahedra and $\mathrm{Mo} / \mathrm{NbO}_{4}$ tetrahedra ${ }^{19}$. A poor fit to the neutron data was obtained upon using the model previously reported for $\mathrm{Ba}_{3} \mathrm{MoNbO}_{8.5}{ }^{19}$ in a high resolution electron microscopy study. 


\begin{tabular}{|c|c|c|c|c|c|c|c|c|}
\hline Atom & $\begin{array}{c}\text { Sit } \\
\text { e }\end{array}$ & $\mathbf{x}$ & $y$ & $\mathbf{z}$ & Occupancy & $\begin{array}{c}U_{11}=U_{22} \\
\left(\AA^{2}\right)\end{array}$ & $\mathbf{U}_{33}\left(\AA^{2}\right)$ & $\mathbf{U}_{12}\left(\AA^{2}\right)$ \\
\hline $\mathbf{B a}(\mathbf{1})$ & $3 a$ & o & o & o & 1 & $0.0165(3)$ & $0.0192(6)$ & $0.0083(2)$ \\
\hline $\mathbf{B a}(\mathbf{2})$ & $6 c$ & o & o & $0.20629(8)$ & 1 & $0.0165(3)$ & $0.0192(6)$ & $0.0083(2)$ \\
\hline $\operatorname{Mo}(\mathbf{1}) / \operatorname{Nb}(\mathbf{1})$ & $6 c$ & o & o & $0.39936(6)$ & $0.926(1)$ & $0.0049(2)$ & 0.0498 (9) & $0.0025(1)$ \\
\hline $\operatorname{Mo}(2) / \operatorname{Nb}(2)$ & $3 b$ & o & o & 0.5 & $0.148(1)$ & $0.0049(2)$ & 0.0498 (9) & $0.0025(1)$ \\
\hline $\mathbf{O}(\mathbf{1})$ & $18 h$ & $0.17212(5)$ & $0.82788(5)$ & $0.10343(2)$ & 1 & $0.0215(3)$ & $0.0140(3)$ & $0.0160(3)$ \\
\hline $\mathrm{O}(2)$ & $9 e$ & 0.5 & o & o & $0.449(2)$ & $0.0240(8)$ & $0.0121(3)$ & $0.0155(4)$ \\
\hline $\mathbf{O}(3)$ & $36 i$ & $0.0850(9)$ & $0.0933(7)$ & $0.3195(2)$ & $0.096(1)$ & $0.0342(2)$ & & \\
\hline
\end{tabular}

Table1. Refined atomic parameters from Rietveld fit of the powder neutron diffraction data recorded on the Gem diffractometer at $290 \mathrm{~K}$. Data were refined in the space group $R \overline{3} m \mathrm{H}$ with $a=5.92744$ (3) $\AA, c=21.0995$ (2) $\AA ; \chi^{2}=$ 2.4, $R_{p}=3.29 \%$ and $R_{W_{p}}=3.24 \% . U_{i j}$ indicates anisotropic thermal displacement parameters. $U_{13}$ and $U_{23}$ are zero.

There was no evidence of an ordered distribution of octahedra and tetrahedra within the cubic layers. A poor fit was also obtained to the model previously reported for the stoichiometrically similar compound $\mathrm{Ba}_{3} \mathrm{VWO}_{8.5^{30}}$ which contains a purely octahedral coordination of vanadium and tungsten.

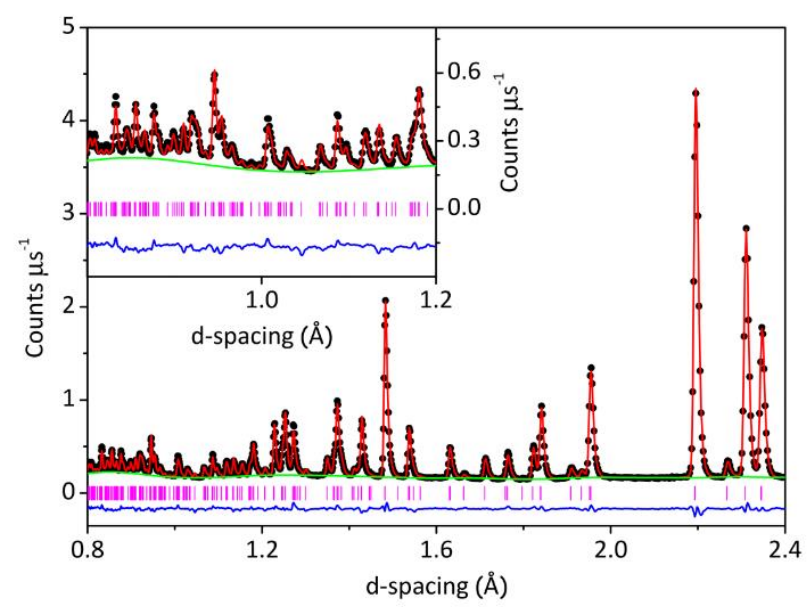

Figure 4. Rietveld refinement fit to the TOF neutron diffraction data of $\mathrm{Ba}_{3} \mathrm{MoNbO}_{8.5}$ at ambient temperature. Neutron diffraction data from the $91.5^{\circ}$ bank detector of the GEM diffractometer is shown. Black dots indicate the observed data, the red line the Rietveld fit, the blue line the difference between the observed and the calculated patterns, the green line the background function and the pink bars are the reflection positions.

Previous electron diffraction ${ }^{19}$ and Raman ${ }^{31}$ studies had clearly indicated the presence of both $(\mathrm{Mo} / \mathrm{Nb}) \mathrm{O}_{6}$ octahedra and $(\mathrm{Mo} / \mathrm{Nb}) \mathrm{O}_{4}$ tetrahedra within the crystal structure.
A hybrid model of the palmierite and $9 \mathrm{R}$ structures was therefore constructed (Figure 3(a), Table 1 ) and an excellent Rietveld fit to this model is obtained $\left(\chi^{2}=2.4, R_{p}=3.29\right.$ $\%$ and $\mathrm{R}_{\mathrm{Wp}}=3.24 \%$ (Figure 4 )). The oxygen content in $\mathrm{Ba}_{3} \mathrm{MoNbO}_{8.5}$ is intermediate between the two structural types. Both the $9 \mathrm{R}$ and the palmierite structures have an (hhc) $)_{3}$ stacking sequence but oxygen vacancies in the cubic layers of the palmierite (hhc) ${ }_{3}$ sequence results in the formation of tetrahedral B cations (Fig. 3). The oxygen atom at Wyckoff position $18 \mathrm{~h}$ is common to both the $9 \mathrm{R}$ and palmierite structures. The palmierite structure also has an oxygen atom at Wyckoff position $6 c$ whereas the $9 \mathrm{R}$ structure has an oxygen atom at position $9 e$. The hybrid model contains oxygen on all three sites and metals on both the $6 c$ and $3 b$ Wyckoff positions (Table 1 ). Refining the oxygen site occupancies results in an overall oxygen stoichiometry of 8.5; the oxygen $(\mathrm{O}(1))$ at position $18 \mathrm{~h}$ is fully occupied and partial occupancy of $\left.\mathrm{O}_{2}\right)$ and $\mathrm{O}_{3}$ ) is observed (Table 1). $\mathrm{Mo}^{6+}$ and $\mathrm{Nb}^{5+}$ have very similar relative scattering powers for both X-rays and neutrons and so it was not possible to determine the ratio of Mo: Nb on each site. It was assumed that the $\mathrm{Mo}^{6+}$ and $\mathrm{Nb}^{5+}$ cations were disordered over the $6 c$ and $3 b$ sites. The Ba fractional occupancies refined to within $\pm \mathbf{1} \%$ of the full occupancy and were fixed at 1.o.

The atomic displacement parameters, $U$, were modelled anisotropically for all atoms. The atomic displacement parameters for the two $\mathrm{Ba}$ ions were constrained to be the same, as were the atomic displacement parameters for $\mathrm{Mo} / \mathrm{Nb}$ on the $6 c$ and $3 b$ sites. Disorder of the oxygen atom, $\mathrm{O}(3)$, within the $\mathrm{Mo} / \mathrm{NbO}_{4}$ tetrahedra was evidenced by large $U_{11}, U_{22}$ and $U_{12}$ values. This was modelled by using a single isotropic $U$ factor for $\mathrm{O}_{3}$ ) and splitting the site as shown in Table 1, Figure 3. The $\mathrm{Ba}(2)$ and $\mathrm{Mo}(1) / \mathrm{Nb}(1)$ cations and the ideal $\mathrm{O}(3) 6 \mathrm{c}$ position are all located on the 3fold axis and the $\mathrm{Ba}(2)-\mathrm{Mo}(1) / \mathrm{Nb}(1)$ distance is $\sim 4.07 \AA ̊$. It 
is proposed that the disorder of oxygen onto the $36 i$ positions arises as a result of the short distance between $\mathrm{Ba}(2)$ and $\mathrm{Mo}(1) / \mathrm{Nb}(1)$ so that the disorder stabilises the structure resulting in longer and more realistic $\mathrm{Ba}(2)-\mathrm{O}(3)$ and $\mathrm{Mo}(1) / \mathrm{Nb}(1)-\mathrm{O}(3)$ bond lengths. Similar structural disorder has been reported for the mixed conducting hexagonal perovskite $\mathrm{Ba}_{7} \mathrm{Y}_{2} \mathrm{Mn}_{3} \mathrm{Ti}_{2} \mathrm{O}_{20}{ }^{14}$. The thermal ellipsoids of $\mathrm{O}(1)$ and $\mathrm{O}(2)$ and $\mathrm{Ba} / \mathrm{Nb}$ atoms are displayed in Figure $3(\mathrm{~b})$. The Mo/Nb sites also exhibit highly anisotropic thermal motion $\left(U_{11}=U_{22}=0.0049(2) \AA^{2} ; U_{33}=0.0498(9) \AA^{2} ; U_{12}=\right.$ o.0025(1) $\AA^{2}$ ). The bond lengths and angles obtained from Rietveld refinement of the crystal structure (Fig. 3(b); Supplementary Table 1 ) demonstrate that the $(\mathrm{Mo} / \mathrm{Nb}) \mathrm{O}_{6}$ and $(\mathrm{Mo} / \mathrm{Nb}) \mathrm{O}_{4}$ polyhedra are distorted in $\mathrm{Ba}_{3} \mathrm{MoNbO}_{8.5}$. Similar bond lengths and angles have been reported for other materials containing mixed tetrahedral/octahedral coordination of $\mathrm{Mo}$ and $\mathrm{Nb}$ atoms ${ }^{32}$.

\section{DISCUSSION}

$\mathrm{Ba}_{3} \mathrm{MoNbO}_{8.5}$ is the first hexagonal perovskite derivative to exhibit significant oxide ion conductivity. $\mathrm{Ba}_{3} \mathrm{MoNbO}_{8.5}$ crystallises with an unusual and unique hybrid structure containing a disordered distribution of $(\mathrm{Mo} / \mathrm{Nb}) \mathrm{O}_{6}$ octahedra and $(\mathrm{Mo} / \mathrm{Nb}) \mathrm{O}_{4}$ tetrahedra. The crystal structure of $\mathrm{Ba}_{3} \mathrm{MoNbO}_{8.5}$ contains intrinsic oxygen vacancies. The $\mathrm{O}(2)$ and $\mathrm{O}(3)$ sites cannot be simultaneously occupied within the structure of $\mathrm{Ba}_{3} \mathrm{MoNbO}_{8.5}$. This leads to the creation of randomly mixed domains of $(\mathrm{Mo}(1) / \mathrm{Nb}(1)) \mathrm{O}_{6}$ octahedra and $(\mathrm{Mo}(1) / \mathrm{Nb}(1)) \mathrm{O}_{4}$ tetrahedra. Locally it is likely that the $\mathrm{O}(2)$ and $\mathrm{O}(3)$ sites compete for occupation. This would imply that movement of oxide ions is via octahedral and tetrahedral interchange and suggests a cooperative motion such as an interstitialcy mechanism.

A single crystal X-ray diffraction study has shown that the high oxide ion mobility observed in $\mathrm{La}_{2} \mathrm{Mo}_{2} \mathrm{O}_{9} 33$ is facilitated by the ability of $\mathrm{Mo}^{6+}$ to adopt variable coordination environments. The same ability has been reported for $\mathrm{Nb}^{5+}$ in the high temperature structure of the mixed ionic and electronic conductor $\mathrm{Ba}_{4} \mathrm{Nb}_{2} \mathrm{O}_{9} 34$. It is highly likely that the variable co-ordination environment for $\mathrm{Mo}^{6+}$ and/or $\mathrm{Nb}^{5+}$ in $\mathrm{Ba}_{3} \mathrm{MoNbO}_{8.5}$ is important for producing a low energy migration pathway for the oxide ions.

The $(\mathrm{Mo} / \mathrm{Nb}) \mathrm{O}_{6}$ and $(\mathrm{Mo} / \mathrm{Nb}) \mathrm{O}_{4}$ polyhedra are also clearly distorted in $\mathrm{Ba}_{3} \mathrm{MoNbO}_{8.5}$ (Fig. 3(b); Supplementary Table 1 ). It has previously been reported that both $\mathrm{d}^{\circ}$ cations $\mathrm{Mo}^{6+}$ and $\mathrm{Nb}^{5+}$ are susceptible to out of centre displacement of the metal-oxygen octahedra as a result of a $2^{\text {nd }}$ order Jahn-Teller distortion ${ }^{35}$. The magnitude of the out of centre distortion increases with increasing formal charge and decreases with increasing size of the cation so that a sizeable distortion is expected for $\mathrm{Mo}^{6+}$. It is therefore likely that the observed distortions of the $(\mathrm{Mo} / \mathrm{Nb}) \mathrm{O}_{6}$ and $(\mathrm{Mo} / \mathrm{Nb}) \mathrm{O}_{4}$ polyhedra, combined with the anisotropic thermal displacement of the Mo/Nb cations and the variable coordination geometry of the $\mathrm{Mo}^{6+}$ and/or $\mathrm{Nb}^{5+}$ cation enables facile mobility of the oxide ions through the anion vacancies in the $\mathrm{Ba}_{3} \mathrm{MoNbO}_{8.5}$ structure. Further computer modelling is required to establish the diffusion pathways of the oxide ions in $\mathrm{Ba}_{3} \mathrm{MoNbO}_{8.5}$.

The bulk ionic conductivity of $\mathrm{Ba}_{3} \mathrm{MoNbO}_{8.5}$ at $600{ }^{\circ} \mathrm{C}$ is comparable to other leading oxide conductors and considerably larger than those reported for other perovskite derivatives such as $\mathrm{NdBaInO}_{4}$ (Fig. 2) which exhibits predominantly oxide ion conductivity over the $\mathrm{pO}_{2}$ range $3.0 \mathrm{x} 10$ ${ }^{19}$ to $3.2 \times 10^{-11} \mathrm{~atm}^{24}$. EMF and conductivity versus oxygen partial pressure measurements, give evidence that oxide ionic conductivity is observed for $\mathrm{Ba}_{3} \mathrm{MoNbO}_{8.5}$ over the $p \mathrm{O}_{2}$ range $10^{-20}-1 \mathrm{~atm}$ at $600{ }^{\circ} \mathrm{C}$. The electronic n-type contribution to the total conductivity observed for $\mathrm{pO}_{2}<10^{-20}$ is most likely due to the reduction of $\mathrm{Mo}^{6+}$ at low $\mathrm{pO}_{2}$; substitution of $\mathrm{Mo}^{6+}$ with the more stable $\mathrm{W}^{6+}$ cation could further increase the ionic conduction window, as reported for $\mathrm{W}$-doped LAMOX materials ${ }^{20}$. $\mathrm{Ba}_{3} \mathrm{MoNbO}_{8.5}$ exhibits good ionic transport number values of 0.99 in air $/ \mathrm{O}_{2}$ and 0.92 in air $/ 5 \% \mathrm{H}_{2}$ in $\mathrm{Ar}$ at $600{ }^{\circ} \mathrm{C}$, which corroborate the results obtained from $\mathrm{pO}_{2}$ measurements. $\mathrm{Ba}_{3} \mathrm{MoNbO}_{8.5}$ is stable under both flowing $5 \% \mathrm{H}_{2} / \mathrm{N}_{2}$ and $\mathrm{O}_{2}$ and presents a wider stability range under reducing conditions than other leading oxide ion conductors such as the $\mathrm{Bi}$ and $\mathrm{Ce}$ oxides 5 . There is also no degradation of the electrical conductivity with time and no evidence of proton conduction. Appropriate chemical doping should result in a further increase of the bulk conductivity so that $\mathrm{Ba}_{3} \mathrm{MoNbO}_{8.5}$ could be an excellent candidate as an electrolyte for intermediate temperature fuel cells upon further chemical modification. Hexagonal perovskite derivatives containing mixed tetrahedral and octahedral geometry warrant further investigation.

\section{ASSOCIATED CONTENT}

Supporting Information is available free of charge via the Internet at http://pubs.acs.org. The supporting information includes detailed experimental data, impedance spectroscopy data fitting, tables of bond lengths and angles, X-ray diffraction patterns, the variation of conductivity with time and the impedance spectroscopy data recorded in a moist atmosphere.

\section{AUTHOR INFORMATION}

\section{Corresponding Author \\ *a.c.mclaughlin@abdn.ac.uk}

\section{Author Contributions}

The manuscript was written through contributions of all authors.

\section{ACKNOWLEDGMENT}

This research was supported by the Northern Research Partnership and the University of Aberdeen. We also acknowledge STFC-GB for provision of beamtime at ISIS.

\section{REFERENCES}

2

3
Goodenough, J. B. Annu. Rev. Mater. Res. 2oo3, 33, 91.

Steele, B.; Heinzel, A. Nature 2oo1, 414, 345.

Malavasi, L.; Fisher, C. A. J.; Islam, M. S. Chem. Soc. Rev. 2010, 39, 4370.

Brett, D. J. L.; Atkinson, A.; Brandon, N. P.; Skinner, S. J.. Chem. Soc. Rev. 2oo8, 37, 1568.

Wachsman, E. D.; Lee, K. T. Science 2o11, 334, 935. 

avljevic, I. E. Angew. Chemie - Int. Ed. 2012, 51, 690. Lacorre, P.; Goutenoire, F.; Bohnke, O.; Retoux, R.; Laligant, Y. Nature 200o, 404, 856.

8 Li, M.; Pietrowski, M. J.; De Souza, R. A.; Zhang, H.; Reaney, I. M.; Cook, S. N.; Kilner, J. A.; Sinclair, D. C. Nat. Mater. 2014, 13, 31.

9 Kuang, X.; Green, M. A.; Niu, H.; Zajdel, P.; Dickinson, C.; Claridge, J. B.; Jantsky, L.; Rosseinsky, M. J. Nat. Mater. 2008, 7, 498.

10 Kendrick, E.; Islam, M. S.; Slater, P. R. J. Mater. Chem. 2007, 10, 3104.

11 Abraham, F.; Debreuille-Gresse, M. F.; Mairesse, G.; Nowogrocki, G. Solid State Ionics 1988, 30, 529. Kendrick, E.; Kendrick, J.; Knight, K. S.; Islam, M. S.; Slater, P. R. Nat. Mater. 20o7, 6, 871.

Ishihara, T.; Matsuda, H.; Takita, Y. J. Am. Chem. Soc. 1994, 116,3801 .

4 Kuang, X.; Allix, M.; Ibberson, R. M.; Claridge, J. B.; Niu, H.; Rosseinsky, M. J. Chem. Mater. 2007, 19, 2884 .

5 Ling, C. D.; Avdeev, M.; Kutteh, R.; Kharton, V. V.; Yaremchenko, A. A.; Fialkova, S.; Sharma, N.; Macquart, R. B.; Hoelzel, M.; Gutmann, M. Chem. Mater. 2009, 21, 3853 . Ling, C. D.; Avdeev, M.; Kutteh, R.; Kharton, V. V.; Yaremchenko, A. A.; Macquart, R. B.; Hoelzel, M. Chem. Mater. 2009, 22, 532.

17 Durif, A. Acta Cryst. 1959, 12, 420.

18 Susse, P.; Buerger, M. J. Z. Krist. 1970, 131, 161.

19 García-González, E.; Parras, M.; González -Calbet, J. M. Chem. Mater. 1998, 10, 1576.

Marrero-Lopez, D.; Canales-Vazquez, J.; Ruiz-Mo-
Irvine, J. T. S.; Sinclair, D. C.; West, A. R. Adv. Mater. 1990, 2, 132.

Kwon, Oh H.; Choi, G. M. Solid State Ionics, 2007, 177, 3057 .

Goodenough, J. B; Ruiz-Diaz, J. E.; Zhen, Y. S. Solid State Ionics 1990, 44, 21.

Fujii, K.; Esaki, Y.; Omoto, K.; Yashima, M.; Hoshikawa, A.; Ishigaki, T.; Hester, J. R. Chem. Mater. 2014, 26, 2488.

Fujii, K.; Shiraiwa, S.; Esaki, Y.; Yashima, M.; Kim. S. J.; Lee, S. J. Mater. Chem. A 2015, 3, 11985.

Krok, F.; Malys, M.; Dygas, J.R.; Bogusz, W.; Abrahams, I. Mol. Phys. Rep. 20oo, 27, 46.

Rietveld, H. M. Acta Crystallogr., 1967, 22, 151. Larson, A. C.; Von Dreele, R. B. General Structure Analysis System (GSAS), Los Alamos National Laboratory, Technical Report No. LAUR86-748 (2004) (unpublished).

Toby, B. H. EXPGUI, a graphical user interface for GSAS, J. Appl. Cryst. 2oo1, 34, 210.

Moessner, B.; Kemmler-Sack, S. J. Less-Com. Met, 1985, 114, 333

31 Brown Holden, A. A.; Reedyk, M.; García-González, E.; Parras, M.; Gonzalez-Calbet, J. M. Chem. Mater. 2000, 12, 2287.

García-González, E.; Parras, M.; González -Calbet, J. M. Chem. Mater. 1999, 11, 433. rales, J.C.; Irvine, J.T.S.; Nunez, P. Electrochimica Acta, 2005, 50, 4385 .
Evans, I. R.; Howard, J. A. K.; Evans, J. S. O. Chem. Mater. 2005, 17, 4074.

34 Dunstan, M. T.; Blanc, F.; Avdeev, M.; McIntyre, G. J.; Grey, C. P.; Ling, C. D. Chem. Mater., 2013, 25, 3154 .

Kunz, M.; Brown, D. I. J. Solid State Chem. 1995, 115, 395 .

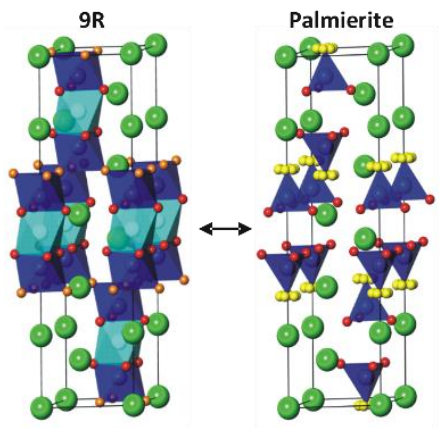

Table of Contents artwork 